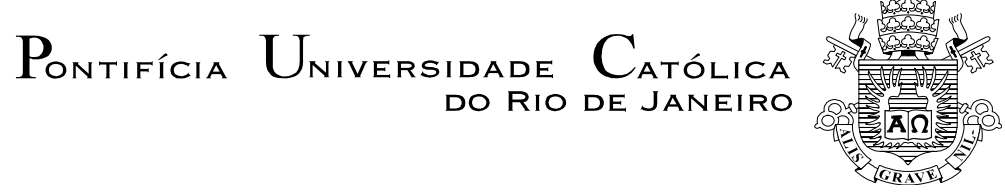

Estela de Jesus Martins

Comunicação Mediada por Computador: a construção do conhecimento no processo interacional de um fórum de discussão

Dissertação de Mestrado

Departamento de Letras Estudos da Linguagem

Rio de Janeiro Março de 2003 


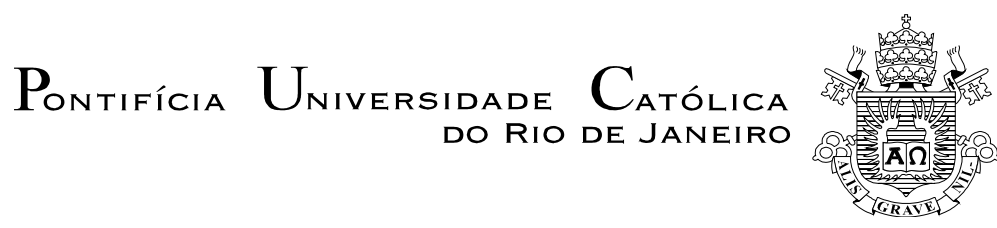

Estela de Jesus Martins

\title{
Comunicação Mediada por Computador: a construção do conhecimento no processo interacional de um fórum de discussão
}

\author{
Dissertação de Mestrado
}

Dissertação apresentada como requisito parcial para obtenção de grau de Mestre pelo Programa de Pósgraduação em Estudos da Linguagem do Departamento de Letras da PUC-Rio.

Orientadora: Profa. Tânia Mara Gastão Saliés 


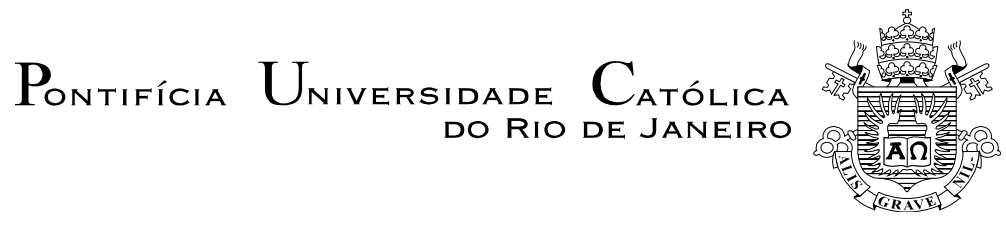

Estela de Jesus Martins

\begin{abstract}
Comunicação Mediada por Computador: a construção do conhecimento no processo interacional de um fórum de discussão
\end{abstract}

\begin{abstract}
Dissertação apresentada como requisito parcial para obtenção de grau de Mestre pelo Programa de Pósgraduação em Estudos da Linguagem do Departamento de Letras da PUC-Rio. Aprovada pela Comissão Examinadora abaixo assinada.
\end{abstract}

Professora Doutora Tânia Mara Gastão Saliés

Orientadora

Departamento de Letras - PUC-Rio

Professora Doutora Vera Lúcia Menezes de Oliveira e Paiva

Departamento de Letras - UFMG

Professora Doutora Lúcia Pacheco de Oliveira

Departamento de Letras - PUC-Rio

Professora Doutora Inés Kayon de Miller

Departamento de Letras - PUC-Rio

Professor Dr.JÜRGEN HEYE Coordenador Setorial do Centro de

Teologia e Ciências Humanas

Rio de Janeiro, de

de 2003 
Todos os direitos reservados. É proibida a reprodução total ou parcial do trabalho sem autorização da universidade, da autora e do orientador.

\section{Estela de Jesus Martins}

Graduou-se em Letras (Português e Inglês) na PUC-Rio (Pontifícia Universidade Católica do Rio de Janeiro) em 2000. Apresentou trabalhos em eventos promovidos pela PUC-SP e pela UCPel em 2002.

\section{Ficha Catalográfica}

Martins, Estela de Jesus
Comunicação mediada por computador: a
construção do conhecimento no processo
interacional de um fórum de discussão / Estela de
Jesus Martins; orientadora: Tânia Mara Gastão
Saliés. - Rio de Janeiro: PUC, Departamento de
Letras, 2003.
190 f. ; $30 \mathrm{~cm}$
Dissertação (mestrado) - Pontifícia
Católica do Rio de Janeiro,
Universidade
Departamento de Letras.
Inclui referências bibliográficas.
1. Letras - Teses. 2. CMC. 3. Linguagem e
4. Ensino e aprendizagem.
comunicação.
Letramento. 6. Inteligência coletiva. 7. Comunidade
de prática. I. Saliés, Tânia Mara Gastão. II.
Pontifícia Universidade Católica do Rio de Janeiro.
Departamento de Letras. III. Título.

CDD: 370 
Ao meu pai, Adolpho Martins, in memorian, pela convicção de que educação é o melhor legado que se pode deixar aos filhos. 


\section{Agradecimentos}

A minha orientadora, Professora Tânia Mara Gastão Saliés, cuja competência, estímulo e parceria foram essenciais para este trabalho.

Às professoras que participaram da Comissão Examinadora.

À PUC-Rio, pelo auxílio concedido, sem o qual este trabalho não poderia ter sido realizado.

À Professora Ana M.B. Pavani e aos integrantes do Projeto Maxwell, pelo acesso e amável cooperação durante a constituição do corpus.

A todos os professores e funcionários do Departamento de Letras, pelo carinho e amizade ao longo desta jornada.

Aos meus colegas de Mestrado, pelo sentimento de união e fraternidade.

A minha mãe, por ter tão sabiamente despertado nas filhas o amor pela leitura.

A todos os amigos e familiares, pela paciência e compreensão nas inúmeras ocasiões em que não pude dar-lhes a merecida atenção.

Ao meu marido Carlos e aos meus filhos Rodrigo e Suzana, pelo apoio, companheirismo, colaboração e vibrante torcida. 


\section{Resumo}

Martins, Estela de Jesus; Saliés, Tânia Mara Gastão. Comunicação Mediada por Computador: a construção do conhecimento no processo interacional de um fórum de discussão. Rio de Janeiro, 2003. 190 p. Dissertação de Mestrado - Departamento de Letras, Pontifícia Universidade Católica do Rio de Janeiro.

As conferências por computador incorporam-se cada vez mais ao dia-a-dia acadêmico, através de programas de ensino a distância e de sua utilização como ferramenta auxiliar no processo de ensino e aprendizagem. Contudo, os estudos têm privilegiado as modalidades sincrônicas de comunicação. As poucas incursões pela assincronia detêm-se nas listas de discussão ou limitam-se a definições no que tange ao fórum. Preenchendo esta lacuna, o presente estudo trata de um fórum de discussão privado ocorrido simultaneamente às aulas presenciais de uma turma de engenharia elétrica da PUC-Rio. O objetivo é descrever e analisar qualitativa e quantitativamente o papel do fórum enquanto experiência discursiva, investigando como se dá a interação e a construção do conhecimento; a possível caracterização do fórum como gênero ou suporte; e o efeito da intervenção do professor no processo. Inspirada pelo sociointeracionismo, a análise focou a freqüência de participação e sua direcionalidade, o fluxo de tópico, a presença social e cognitiva via índices lingüísticos que indicassem afeto, atitude, metacognição, complexidade lexical e sintática. Os resultados sugerem que o fórum deveria ser investigado dentro de um arcabouço de estudos de gênero. Sugerem também que o fórum é um gênero e funciona como uma comunidade de prática, favorecendo a reflexão crítica através de práticas discursivas dialógicas, a aprendizagem de elos coesivos na produção textual, o processo de letramento e de desenvolvimento da "inteligência coletiva". Aparentemente, o fórum de discussão contribui para a construção da identidade social e profissional dos participantes.

\section{Palavras-chave}

CMC; fórum de discussão; práticas discursivas; dialogismo; comunidade de prática; metacognição; construção do conhecimento; letramento; inteligência coletiva. 


\section{Abstract}

Martins, Estela de Jesus; Saliés, Tânia Mara Gastão. Computer mediated Communication: the construction of knowledge in the interactional process of a private forum. Rio de Janeiro, 2003. 190 p. MA. Dissertation - Departamento de Letras, Pontifícia Universidade Católica do Rio de Janeiro.

Computer conferencing has been increasingly incorporated to academic routines, either in distance learning or in the regular classroom, as a support. Nevertheless, the literature has focused on synchronous CMC; its few incursions into asynchrony refer to discussion lists or limit themselves to defining the forum. To fill up such a gap, this study focuses on a private forum held simultaneously with classroom learning by undergrads in Electrical Engineering, at PUC-Rio. Its objective is to describe and analyze, quantitative and qualitatively, the role of the forum as a discursive experience, investigating how interaction and knowledge construction take place; the possibility of characterizing the forum as a genre; and the effect of teacher's intervention in the process. Inspired by sociointeractionism, it analyzed participation and interactional direction, the topic framework, social and cognitive aspects signaled by linguistic devices that represent affect, attitude, metacognition, lexical and syntactic complexity. Results suggest that future studies need to address the forum within the paradigm of genre study. It also suggests that the forum is a genre and functions as a community of inquiry, leading to critical thinking by means of dialogical discursive and literacy practices, learning of coesive ties in writing, and the development of "collective intelligence". Apparently, it contributes to the construction of the social and professional identities of the participants.

\section{Keywords}

CMC; forum of discussion; discursive practices; dialogism; community of inquiry; critical thinking; knowledge construction; literacy; collective intelligence. 


\section{Sumário}

$\begin{array}{ll}\text { 1. Introdução } & 13\end{array}$

2. CMC: o Fórum de Discussão 20

2.1 Introdução 20

2.2 Sincronia e Assincronia 21

2.3 Listas de Discussão e o Fórum 24

2.4 Resumo 28

3. Fórum, Linguagem e Comunicação 29

3.1 Introdução 29

3.2 A linguagem do fórum 31

3.3 O fórum como evento comunicativo 35

$\begin{array}{lll}3.4 & \text { Resumo } & 44\end{array}$

4. Fórum, Ensino e Aprendizagem, e a Construção do Conhecimento 45

4.1 Introdução 45

4.2 A questão do letramento e as novas tecnologias 46

4.3 A inteligência coletiva 49

4.4 Os estudos que tratam do fórum 51

4.5 A comunidade de prática e a construção do conhecimento 53

4.6 O papel do professor 59

$\begin{array}{lll}4.7 & \text { Resumo } & 60\end{array}$

5. O Estudo: Metodologia de Pesquisa 63

5.1 A natureza da pesquisa 63

5.2 O contexto 64

5.3 O Banco de Dados 65

$\begin{array}{lll}5.4 & \text { Os sujeitos } & 68\end{array}$ 
5.5 Os procedimentos de coleta de dados 70

5.6 As perguntas de pesquisa 71

5.7 Os procedimentos de análise 71

6. Análise dos Dados e Discussão dos Resultados 92

6.1 O perfil dos alunos 92

6.2 A análise do fórum 98

6.2.1 Qual o papel do fórum no processo
de ensino e aprendizagem?

6.2.1.1 O fórum como evento comunicativo 98

6.2.1.2 Freqüência e estrutura de participação no fórum 102

6.2.2 Como se deu a construção do conhecimento no fórum?

6.2.2.1 O fórum e as funções da linguagem 117

6.2.3 Que relação há entre o professor e a dinâmica interacional do fórum?

\subsubsection{O papel do professor na prática} do fórum

6.2.4. Como caracterizar o fórum: gênero ou suporte?

6.3 Resumo

7. Considerações Finais 142

7.1 Principais Contribuições 143

7.2 Recomendações e Limitações Metodológicas 144

8. Referências bibliográficas 146

9. Anexos
A O corpus
154
B Questionário etnográfico
185
187
D Lista de Alunos Participantes do Fórum
190 


\section{Lista de figuras}

Figura $1 \quad \mathrm{CMC}-$ Sincronia vs. Assincronia 21

Figura 2 CMC e Sincronicidade 23

Figura 3 A Comunidade de Prática 57

Figura $4 \quad$ O fórum como comunidade de prática 61

Figura 5 Distribuição física da sala de aula 66

Figura 6 Banco de Dados 68

Figura $7 \quad$ A Turma e o Fórum 69

Figura 8 Demografia da Sala de Aula versus a do Fórum 69

Figura 9 Identificação dos Informantes $\quad 71$

Figura 10 A etnografia da comunicação 73

Figura 11 Exemplo de Seqüência Simples 73

Figura 12 Exemplo de Réplica Dupla 74

Figura 13 Exemplos de Mensagem Alunos/Grupo 74

Figura 14 Seqüência Aluno/Aluno 74

Figura 15 Seqüência Aluno/Professora 75

Figura 16 Roteiro de Resposta à Primeira Pergunta de Pesquisa $\quad 76$

Figura 17 Roteiro de Respostas à Segunda Pergunta de Pesquisa 83

Figura 18 Roteiro de Respostas à Terceira Pergunta de Pesquisa

Figura 19 Roteiro de Respostas à Quarta Pergunta de Pesquisa $\quad 89$

Figura 20 Procedimentos de Análise 91

Figura 21 Número de Alunos por Período Letivo 92

Figura 22 Faixas Etárias 93

Figura 23 Escolaridade dos Pais 93

Figura 24 Atividades Acadêmicas Extra-Curriculares $\quad 94$

Figura 25 Detalhamento das Atividades Acadêmicas Extra-Curriculares 94

Figura 26 Investimento Cultural 95

Figura 27 Freqüência em Ambientes Virtuais 95 
Figura 28 A Opinião dos Alunos sobre o Fórum 96

Figura 29 A etnografia da comunicação do fórum 103

Figura 30 Freqüência de Participação por Tópico 104

Figura 31 Estrutura de Participação - Tópico 1108

Figura 32 Estrutura de Participação - Tópico 2

Figura 33 Estrutura de Participação - Tópico 1: direcionalidade

Figura 34 Estrutura de Participação - Tópico 2: direcionalidade

Figura 35 Fluxo de Tópico no Fórum - Tópico $1 \quad 120$

Figura 36 Fluxo de Tópico no Fórum - Tópico 2

$\begin{array}{lll}\text { Figura } 37 & \text { Presença Social } & 128\end{array}$

Figura 38 As Funções da Linguagem no Fórum: predominância 129

Figura 39 As Palavras Abertas no Discurso do Fórum 137

Figura 40 Complexidade Sintática 139

\section{Lista de tabelas}

Tabela 1 Características Gerais do Fórum 27

Tabela 2 Caracterizando o Fórum 41

Tabela 3 As Funções da Linguagem de Jakobson 77

Tabela 4 Determinação do Sub-tópicos 80

Tabela 5 Função Interpessoal: a Presença Social 82

Tabela 6 Principais Sub-tópicos do Fórum 122

Tabela 7 Freqüência de Retomada de Sub-tópicos 123

Tabela 8 Indicadores da Presença Social 127

Tabela 9 Tempo de Retorno do Professor: Tópico 13

Tabela 10 Tempo de Retorno do Professor: Tópico 2133

Tabela 11 Variedade Lexical do Fórum 136

Tabela 12 Densidade Lexical do Fórum 137

Tabela 13 O Tamanho das Sentenças 138 